
\title{
3 Research Square \\ Politicking with Health Care and Its Implications for the Attainment of Universal Health Coverage
}

Aloysius Odii ( $\nabla$ aloysius.odii@unn.edu.ng )

University of Nigeria https://orcid.org/0000-0002-2222-0835

Pamela Ogbozor

Enugu State University of Science and Technology

Charles Orjiakor

University of Nigeria

Prince Agwu

University of Nigeria

Obinna Onwujekwe

University of Nigeria

\section{Research}

Keywords: Primary Health Centre, Politicking, Universal Health Coverage, Power, Politics

Posted Date: March 5th, 2020

DOI: https://doi.org/10.21203/rs.3.rs-16088/v1

License: (c) (1) This work is licensed under a Creative Commons Attribution 4.0 International License. Read Full License 


\section{Abstract}

Background Primary Health Centres (PHCs) are acknowledged key to the achievement of Universal Health Coverage (UHC) owing to their closeness to the grass-root and the constant patronage by low- and middle-income class citizens. An impediment to the efficiency of PHCs is the nature of politics on-going in its operation beginning from its physical construction, employment of staff, among others. This study provides evidence of politicking marring the efficiency of PHCs as well as possible solutions to the issue.

Method The study was carried out in eight purposively selected PHC facilities drawn from three local government areas in Enugu State, southeast Nigeria. Data were collected using in-depth interviews (IDIs) and focus group discussions (FGDs). The IDIs involved sixteen participants that cut across frontline health workers, heads and supervisors of health units at the local governments, and chairpersons of the health facility committees (HFCCs). In addition, four FGDs were held with male and female service users of the facilities. Findings It was discovered that certain powerful community members influenced the locations of PHCs, even when the general community is disfavoured by such decision. Powerful group of persons equally influence the recruitment and sanctioning of healthcare staff. The consequences include weak patronage of the facilities and poor healthcare delivery. Of the several solutions, obtaining localised support from powerful persons in the community to enforce fairness featured strongly.

Conclusions The politics around primary healthcare is a threat to the achievement of UHC, since it discourages patronage and encourages inefficiency of healthcare staff. To overcome this, there is the need to facilitate genuine participation of community members and implementing local actions and policies in the facilitation of PHCs, and also, rapidly addressing the excesses of powerful groups and individuals. Key words: Primary Health Centre; Politicking; Universal Health Coverage; Power; Politics

\section{Background}

Universal Health Coverage (UHC) means availability of relatively affordable healthcare to everyone [1]. It underscores the need to make health care physically accessible, financially affordable and social/culturally acceptable while ensuring proper coverage: which is that the people who need an intervention actually got it regardless of where they reside. Also, it operationalizes those Sustainable Development Goals that reflect good health, wellbeing and reduced inequalities. A cornerstone to its achievement is strengthening the efficiency of Primary Health Centres (PHCs), known to serve the health needs of the grass-root population usually comprising persons with low resources and uninsured [2]. PHCs are strengthened by recruitment of qualified staff with adequate skill mix and strategic siting of its location on major roads in the community and active travel routes to improve access [3]. Siting of health centres goes beyond choosing a plot of land but considering other factors such as visibility and proximity that improves access [4]. Despite its importance, strategic siting of PHCs are ignored or given little attention [5]. Aside poor siting, other challenges affecting health care delivery in PHCs includes the recruitment of unqualified staff as well as truancy, in the form of absenteeism $[6,7]$. 
The health sector, like other sectors, is political in nature [8]. Although rarely acknowledged or stated, politicking can be the explicit or implicit causes of many challenges experienced in the siting, operation and functioning of PHCs. Politicking serves as an approach through which people with power and influence obtain desired result or outcome. Arguably, politicking is associated with human nature and the human nature drive is rooted in power endearing that is derived from tasks distribution and delineation of ranks [9]. People with power and influence often use it to get ahead of others, more especially when resources are scare or when rules are easily broken or circumvented without consequences.

Evidence of politicking among health workers in a hospital setting was acknowledged by Stalter and Arms [10]. Through politicking, powerful and influential health workers decide the outcome of a process (i.e. who is punished, who gets what benefits, etc.). In health facilities where opportunities and promotions are not based on merits, people with power or those connected with people with power often hijack the outcome, this connects with the common saying, that 'it's not what you know, it's who you know' [11]. In short, unequal opportunities makes it inevitable for persons to politic and influence the process [12]. This is possible because health facilities, like other organisations, are structured like a pyramid thereby making it inevitable for the existence of high rate of internal politicking [13]. Senior health workers in health facilities holds more power and can easily control the junior to attain their personal interest. In like manner, junior health workers can influence certain decisions by aligning with more powerful individuals within or outside the facility. Such well-connected junior workers can equally avoid being disciplined when they engage in corrupt practices like absenteeism [14]. There is also the explanation by Robbins and Judge [15], that some individuals are endowed with the Machiavellian personality characterised by the act of using politics to manipulate policies, rules and regulations to achieve their self-interest. Besides health workers, community members and stakeholders with power and influence may equally affect the outcome of decisions surrounding the siting, functioning and operation of health facilities [16].

The consequences of politics in the health sector may include the siting of health centres in locations that satisfy political interests against the desires of the general community members. Also, powerful individuals determine who works in these facilities, even when these persons could be incompetent or unqualified [6]. This often leads to an inefficient or poorly patronized PHC, forcing healthcare service users into patronizing higher and/or private facilities and incurring higher financial expenses that could be relatively catastrophic [17]. Some could resort to alternatives to orthodox medicine and most likely to face damaging effects. It is therefore important to underscore the dimensions of local politics ongoing at the primary healthcare level, so as to chart interventions that will scale up the efficiency of PHCs, increase patronage, and ultimately improve the chances of Nigeria in achieving UHC.

Attempt to deliver adequate health care in PHCs are hampered by many challenges one of which is poor implementation due to politics of who gets what, when and how [18]. Across literatures, evidence of politicking in the health sector are often directed at the federal and state level of healthcare with particular focus on autonomy, resource control, and remuneration. But since the primary health centre is highly recognized as the epicentre of the efforts to attain UHC, the nature of politics within it should as 
well be x-rayed to reveal disruptive interests of persons at the local context that might affect access and its utilization, that hinders the attainment of UHC. The Anti-Corruption Evidence (ACE) framework on anticorruption could be useful in reducing the excesses of political actors in PHCs. The approach seeks to identify corrupt processes that can be addressed and reversed with feasible policy while capturing the interest of powerful stakeholders that will benefit [14]. This approach, according to Khan, Andreoni, and Roy [19], has the capacity to improve development outcomes.

Finally, financial constraints have been the focus of most literatures on the major barriers towards achieving UHCs, but progress in global health have led to the recognition and acceptance of the need to interrogate other barriers beyond the financial model [20]. One of the barriers that demand careful examination is structural and institutional barriers created by interferences from political actors, stakeholders and influential persons on key issues surrounding the siting and functioning of PHCs. Hence, the study examined the effects of politics in health centres that create structural and institutional barriers preventing PHCs from contributing to the achievement of health goals such as UHC. The study is timely because of importance of attainment of UHC by 2030 which all efforts are geared towards.

\section{Methods}

\section{Study setting}

Data was collected in Enugu, a south-eastern state in Nigeria. Enugu state has a population of 3,267,837 with an annual growth rate of $2.8 \%$ [21]. Health facilities in the state include six district hospitals, 36 cottage hospitals, and over $366 \mathrm{PHCs}$, including comprehensive health centres [22]. Although there are 17 local governments in Enugu State, the study was conducted in three purposively selected Local Government Areas (Igbo-Etiti LGA, Oji River LGA, and Nsukka LGA). Because of the peculiarities of the area, Nsukka was carved into two regions to capture both the rural and urban characteristics. The rural area in Nsukka that was used for the study was Ibagwani Development Centre while the urban was Nsukka town.

\section{Selection of Study Participants}

Sixteen participants were purposively selected for the study and they comprised of four health workers (a nurse, two CHEWs, and a midwife), four health facility committee chairmen, four OICs, and four Heads of Department for health. Introduction letters explaining the aim of the research was sent to all the selected health centres. Subsequently, we visited the selected facilities and sought their consent after explaining the study and highlighting the benefits and risks. Interviews were scheduled with consenting participants on days and times that were convenient. The leader of Health Facility Committees (HFCs) in each health selected facilities were approached and equally informed of the research and they all agreed to participate in the study. All In-depth interviews were conducted in a quiet space at the health facility. 
In addition, the researchers also conducted four Focused Group Discussions (FGD), one in Igbo-Etiti and Oji River LGA and two in Nsukka LGA (Nsukka town and Ibagwani Development Centre), with male and female service users. FGD participants were selected based on these criteria (1) Individual should be 18 years or older, (2) residents in the community hosting the health centre and (3) usage of the health centres within the last year (2018). They were recruited through the assistance of the HFCCs who are community representatives for each PHCs. Adequate consents were sought before interviews were conducted.

\section{Data collection}

IDIs and FGD were used to elicit data in September, 2018. The IDIs were conducted with facility heads or OICs, frontline health workers, HFCCs, and heads and supervisors of the health units at the selected local government areas. The FGDs were used to elicit responses from the service users. The discussion guides were collectively developed by the researchers so they could conduct the interactions uniformly, even at different times. The guides were first pre-tested in a local government area not selected for this study which helped to check for inconsistencies before the main data collection. IDIs were conducted at preferred venues of the informants, while the FGD were organized at central locations away from the environs of the facilities, so as to allow participants feel free to air their views without considering if health workers at the facilities were listening to them. The English and Igbo languages were used all through the interviews, since the researchers and respondents were fluent in both languages. All interactions were capped at between 30 minutes and an hour. For ethical reasons, all participants were promised anonymity and an informed consent form that detailed the essence of the study. They signed on the informed consent forms, indicating wilful participation and full recognition that conversations were recorded with a recording gadget. Finally, the questions we asked captured the process of siting a facility including roles of community members, as well as the identification of powerful persons in the communities and their roles toward the organization of the PHCs from the building process.

\section{Data analysis}

Data were analysed using thematic analysis developed by Braun and Clarke [23]. This was used to identify key information and coding of transcripts. All the interviews were transcribed into English language, then the researchers read the transcripts multiple times to ensure that they are familiar with the contents. Based on the knowledge of the corpus, we assigned codes using open coding, such that units of texts were assigned code(s). Several research meetings were held to harmonise the coded corpus to ensure consistency. The codes were further aggregated into themes. Verbatim quotes were used to illustrate the narratives of the participants in each thematic area. 


\section{Results}

\section{Sociodemographic characteristic of respondents}

A total of 16 people participated in the IDIs (see table 1 and 2). They include OICs, HFCCs, Midwives, HODs, and CHEWs. Participants' ages range from 25-61years. All the HFCCs and HODs are males, except the HOD of Ibagwani Dev. Centre. In addition, four FGDs were conducted (see table 1 and 2), comprising of two women and two men groups. There were 8 participants for each FGD.

\section{(Table 1)}

\section{(Table 2)}

Participants discussed a wide range of issues that captured politics and the role of influential persons in daily functioning of PHCs. Analyses of their responses nevertheless revealed four themes: 1) Individual's interest in the siting and building of health facilities; 2) relationship with influential persons and the recruitment of staff; 3) political interference in the sanctioning of defaulting health workers and 4) interventions to politicking in PHCs.

\section{Individuals' Interests in the Siting and Building of Primary Health Centres}

We found that community members are actively involved in the siting and building of PHCs. Those in need of health centres are often required to provide lands and equally participate in the building process by the local government health authorities. Typically, communities map out communal lands for the project or formally request for the land belonging to private individuals. One of the participants, a HOD in one of the local governments, recounted the procedure:

Some report their need..., they would say they want a health centre in their area, we would ask them if they have a land to spare and if they have then we would ask them to choose a place where the facility would be built (19). 
Most times, communal lands are not available leading to the formal request for lands belonging to private individuals. In some cases, clash of interest occur as land owners engage in local politics to donate lands for the health centre and this often lead to poor location and other challenges that mar access. Illustrative quotes from one of the health committee chairmen and an OIC recounted this ordeal:

Yes, I think that is what happened here, there was some form of competition... because as you can see this facility is not sited along the road even though the structure here is wonderful. So, I think they placed it here so it would benefit some persons (17)

Like I said before, assuming we have land or we are united then the health centre would have been built around the town but as you can see it was taken almost to the boundary between us and Obimo, sometimes they are attacked by thieves (10).

Participants revealed that politicking to influence the siting of PHCs is sometimes driven by the desire to ensure that the facility is situated closer to landowner's homes. Also, participants reported that some individuals not only donate lands but fund the building process. This gesture reportedly has political undertone as it would later be used for campaign to earn votes, loyalty and allegiance. These were captured in the following quotes made by one of the OICs and HFCCs.

When they wanted to build the facility, the godfathers would be saying it must be at a particular location where it is close to his place not considering the road and the people" (1).

They do that so that later on they could use it for campaign saying that they did this and this, so it is just to boost their ego and not a centralized opinion (10).

Thirdly, we found that part of the reason people politick in the siting of PHCs is to position themselves for employment opportunities. Participants reported that those who donate lands do so in the hope that such gesture would be exchanged for employment opportunities upon completion of the facility. This does not have any legal backing as landowners are sometimes disappointed by the government authority. One of the participants in the FGD session pointed to another participant as the one who donated the land for the building of the community health centre and claimed that he was duly compensated: 
It is one of us that gave the land and not the government. He (pointing to one of the participants) is the one that gave out the land so the facility can be built. So government compensated him by asking him to bring in people that would work there, like security man (18)

But the participant who donated the land revealed that he was promised employment opportunity and that the promise is yet to be fulfilled:

I am the person that gave them my land..., even, the things they promised me for the land, they are yet to fulfil it. They promised me that I would be given opportunity to bring in workers but I am yet to get such opportunity. In fact, government neglected us in that place so it not worth talking about (18)

Politicking was found to delay the siting and building of PHCs as powerful landowners clash over whose land will be used. In the end, it could lead to the siting of the facility in isolated and hard to reach areas that are without electricity, water and security. Also, disagreements in the process of siting health centres discourage community members from utilizing the facilities as oppositions reportedly spread fake news and plant traditional birth attendants very close to the facility. These lead to poor motivation to work and encourages absenteeism among health workers, and on the part of community members, it reduces access to health centres. An illustrative quote from two participants in the IDI, a HOD and an HFCC, captured it this way:

When I told the villagers to give me a site to build the health centre, do you know that in my village they delayed for two years without raising a site? And what makes you think that after those arguments and fights the health centre would function well when it is located in an isolated place? There is a cottage hospital in Obimo, it was closed down because of politics, yes, because of politics!... finally, they built the hospital in a location that is inaccessible and isolated and you expect a health worker to stay in a place without fence, security, electricity or water to live there and those same people who fought against getting a site would want to bring the hospital down by planting some Traditional Birth Centres (TBCs) very close to the health centre and even tell people not to go to the health centres but to go to some TBC just to make sure that no one uses the health centre (7)

It makes the health centre not to function as it should because those people whose voices are not heard during the siting of the primary health centre live close but they prefer seeking health care farther away 


\section{Relationship with Influential Persons and the Recruitment of Health Workers}

Health workers reported some form of relationship with people in (political) authority. Health workers may be friends, relatives, or god-children to people in authority and these people influenced their recruitment in the PHCs. One of the health workers, a CHEW recounted how she was employed:

what happened was that there is this brother of ours that works there then so from time to time I kept on telling him that I need a job and he kept assuring me that whenever there is an opportunity he will let me know. Eventually, he helped me secure this job (17).

There were suggestions that political influence in recruitment is more widespread in recent times as health workers identified to be recruited with political influence were said to be dominantly junior workers and newly employed staff:

Almost all these junior workers were given jobs by politicians (15).

The politically powerful do not stop at assisting their relations to gain employment, they also assist them with other opportunities at their workplace in terms of scheduling them for attractive training opportunities. Illustrative quotes from one of the HFCCs captured it this way:

Yesterday I experienced it... so you find out that those that are the highly ranked people would like their relations to participate, so they would come to the training and ensure that their (relations) names are there (10).

Furthermore, the study found that one of the dangers of allowing influential persons to influence the recruitment of staff is the employment of unqualified persons in the place of qualified ones. Thus, the basis for employment into primary health centres is tilted towards the connection a health worker has rather than the qualification, thereby leading to the recruitment of unqualified persons. Health workers recruited on the grounds of political connections feel less obliged to report to work: 
The recent graduates we have are very intelligent but they don't get the job because they have no one to connect them. Everything is about politics because most of the people you see there are related to one politician or the other (18)

the implication is that they would employ the wrong people, like in health, when I came on seat, I raised an alarm because I met some unqualified staffs and it became a case and I told them when I question a staff I would know if she knows what she is doing or not (5).

Let me say you are one of the stakeholders at the local government... you have every right to get workers from your place because you are a politician even though those who you brought might still be studying and wouldn't come to work, yet they get paid. (10)

Service users who participated in the study complained of the low quality of health workers stationed at the primary health centres. This affects their trust in health workers at PHCs and consequently leads to low utilisation. Two of the participants in the FGD session indicated that:

As for me, for those coming from Oji, they know nothing about nursing except only one of them. The rest are only qualified to be cleaners. I can't even allow them to inject my son (18).

If you get a doctor to interview them, you would be shocked that they would not be able to say anything because they are not qualified. You can even go ahead and interview them now and push out those ones that know nothing (laughter from the background) (18)

\section{Political Interference in the Sanctioning of Defaulting Health Workers}

The primary health centres, as an organization, needs sanction to deter health workers from defaulting organisational rules. However, the study found that interferences from persons in powerful positions prevent this from taking place and equally affect the performance of the facility. Difficulties experienced in sanctioning staff could be traced to the fact that many health workers were employed through the help of people in corridors of power. As one of the HODs observed, there is always a tendency for them to 
protect who they helped to gain employment. Therefore, when they default and are about to be punished, they plead with the person who influenced their employment to intervene.

When you employ someone you would try to give her security so when the person has a problem she would try to link up to their brother, uncle, in-law or anybody called their Godfather" (19).

Sometimes the OIC feels like reporting people (hissed) in short I don't know how they see it... but most of us are afraid ... I don't know about others just myself" (15).

Some would call politicians and they would question you on why you had to remove a staff. I did a transfer when I started my job and since last year I have been fighting the war because of it (7)

yes. I told you about when I had a clash with them about this case and the next day I was given a letter to vacate my position as the health committee chairman, the letter is still in my house (3).

Similarly, we found protection of health workers may not always be from politicians or influential persons in the community but from their senior colleagues. In some cases, health workers who are in good relationship with a senior health worker often have some form of protection when they default. But, other workers without such privilege would often be disciplined when they commit the same offence. Such relationship may be with the OIC of the facility or the HOD. As noted, if there is pressure to discipline the staff, they are instead transferred to another facility where they enjoy greater liberty. One of the health committee chairmen narrated it this way;

When there is clash and a superior person like OIC or NIO has a quarrel with the junior staff who misbehaves or goes against the ethics of health..., if she is persistent and get reported to the HOD, he influences the sanctioning of the junior staff then the best thing the HOD does is to change the unit of that worker or get her transferred to a place where she can easily influence the authority of other workers to the benefit of the junior worker probably who is related to her (laughs) (10)

Our findings also show that interference from persons in authority positions in the sanctioning of staff often leads to insubordination and lack of proper decorum in the health facility. This is because protected 
staff know that sanctioning them has consequences. One of the participants, a head of department captured it this way;

It makes some of them arrogant. They would tell you to do anything you like because they have "Abraham" as a father and when you follow it civilly, you would find out that the person has someone that would make you lose your job (19)

I invited him, gave him the query and when he was done reading it he threw it and walked away...the committee found out that the OIC was behaving in that manner because he has someone, I wouldn't call names, to protect him (19).

Under normal circumstances, the junior workers are meant to be accountable to the superior in their unit but because of the interference, things go wrong (10).

\section{Interventions to politicking in PHCs}

Our study also revealed strategies that could help reduce eminent politicking during the siting of health centres. One strategy that was prominent in the data was a clear orientation of the priorities and focus of the primary health centre which could help reduce scuffles for supremacy that inhibits the proper location of health facilities. An illustrative quote has it that stakeholders and community members should be consulted and sensitized on the importance of locating health centres in strategic places:

Before siting the facility, the people through the traditional ruler should be consulted and sensitized of the importance of health centres and then advised to present land that is at the centre of the community. If the facility is sited at the centre, people would utilize it better (17)

Another suggested strategy that could help reduce political interference in the recruitment and sanctioning of staff in the health sector is the synergy between government authorities and community stakeholders. Individuals alone cannot stop political influence and interference because they do not have the power to, but synergy with stakeholders, health workers, and government at the local and state level would go a long way. Such synergy can enable a higher tier of authority (e.g. the state government) to 
directly implement sanctions when political influence at the local government level is protecting and errant staff. According to a health committee chairman,

If the person cannot be punished at the local government level, then it can be taken to the state level where such staff might not have those in their favour (20).

Achieving these would however mean getting powerful community members like the traditional ruler or chairman of the community to partner with health workers, their managers, and government at both the local and state level to support the anticorruption efforts. As the study found, traditional rulers could petition errant health workers and follow it up to ensure it is enforced. Similarly, when the chairman of the local government is fully involved in the petitioning, staff compliance is high. An instance of commitment displayed by the chairman of the local government in an attempt to discipline staff with political connection was captured by one of the HODs, he opined that,

Well, the one I experienced was the intervention of the former chairman of the local government of Oji River, I issued a query and he followed it up to make sure that the staff obeyed... and the staff realized her mistakes (19).

\section{Discussion}

The study explored politicking in PHCs. Specifically, it examined the influence of powerful and influential persons on the location and functioning of PHCs. One of the key issues is the location of the facility. The data suggests that siting and building of PHCs is a problem because of politicking among landowners and other influential persons. Participants reported that health centres are built on community lands but in some cases there are no available land, leading to the request and use of lands of private individuals. Clash of interest often occur as individuals politick to influence the facility location, resulting in the siting of the facility in hard to reach areas. This confirms the argument of Dell'Ovoa et al [5] that the multiplicity of stakeholders with powers and interest usually complicates the process of site selection which in most cases reduces access to the proposed facility. It was reported in our study that politicking over PHCs location delay the building process, and this justify the argument of Oluwamotemi [24] that scuffles between landowners even on projects leading to development hinder the implementation of the projects. Similarly, this finding also agrees with that of Rasak [25] that poor siting usually affects access and utilisation of health centres. According to the findings of Alfaqeeh [26], when PHCs are located in places far from service users, it not only delays the time it takes for them to reach the facility, it discourages them from using the facilities as well. 
Individuals politick over siting and building of PHCs to ensure it is closer to their homes and for political reasons, which can later be exchanged for political support such as being voted for during elections. These practices are possible because of the nature of relationship existing between politicians and health officials [14]. Overall, the consequences of politicking with the siting of PHCs among landowners is that it leads to poor access, refusal to use the facility by oppositions, absenteeism, low utilisation, delay in the building of the facility, etc. This slows the progress towards UHC by hampering equity in access to healthcare and further increase the cost of seeking care.

Another finding suggested by our data was that politicking also exists in the recruitment of health workers for PHCs. This, according to Onwujekwe et al [14] is one of the least frequently reported forms of corruption in the health sector. In our study, we found that most health workers have some form of relationship with persons in key positions in the society i.e. politicians who equally played the role of godparents by influencing their recruitment. The god parents do this to maintain relevance and further exert influence in the community. Ojo, Lamidi, Odewale, Shiyanbade \& Ihemeje [27] described this as patronage relationship or network where the clients are provided with their needs while the patron enjoys political legitimacy and authority. Furthermore, godparents also influence workplace opportunities such as training and other benefits available to health workers. There are consequences to these, our data revealed that many of the workers are not qualified, since employment is heavily influenced by political connection. Sharma [28], Vian [29] and Lewis [30] similarly reported the existence of politically motivated appointments of unqualified persons in Nepal, Kossovo and Ethiopia, and the Dominican Republic, respectively.

The consequences of recruiting unqualified health workers are that service users lose trust in the health centres and reportedly refused to take their children to PHCs to avoid disastrous outcomes. This is consistent with the findings of Ogbuabor and Onwujekwe [31] that when users lack confidence in public health facilities, utilisation of services reduces. Lack of trust of health workers may lead to members seeking healthcare in expensive places or from alternative sources such as TBAs [32]. This also slows the progress towards UHC since the quality of service obtained is not good enough to improve health and those who seek alternative services may incur more expenses.

Finally, our data raised concerns over the level of political protection that health workers who have powerful and influential persons enjoy. Patronage relationship was again revealed in the data as politically connected health workers disobey without consequences. Politically connected staff may likely not be punished over misconducts like absenteeism. Similarly, Callen et al [33], found in their study that doctors connected to politicians absent more frequently than others. In our study, we found that managers who attempt to punish a politically connected staff often bear the consequences, that may include being queried instead. This is consistent with the findings of Ogbuabor and Onwujekwe [31] that OICs are afraid to query junior staff because of interference of political actors. This discourages managers from taking disciplinary actions, leading to insubordination and complacency at the health centre. Junior staff with protections are noted to be arrogant and unaccountable to their superiors thereby affecting the functioning of the centre. This equally affects the quality of health services offered thereby 
slowing the progress towards UHC. Findings in our previous work also revealed that health worker's absenteeism is also brazen where political protection exists [34]. It is important to add that in some cases, the protection of health workers may not be from external figures like politicians but managers or OICs themselves who choose to favour certain staff over others. This has been identified as 'rule by law' and an 'adverse context' for governance in the case where anticorruption reforms fail due to selective or partial enforcement of policies in the Anti-Corruption Evidence (ACE) framework [19].

Our study also revealed important strategies that have the capacity to reduce politicking at the health centres. In a bid to curtail the politicking experienced during siting of PHCs, Local/state government must sensitise the host community and other important stakeholders of the sensitivity of locating the facility in strategic places. In addition, there should be some sort of community consensus after the orientation and a feasibility study on the proposed site. Moreover, regular orientations and seminars over the functioning of the PHCs should prioritised. Also, the importance of merit in the recruitment of health workers must be emphasized. However, because powerful persons can influence appointments, the process should be transparent with active involvement of community stakeholders. In other words, the process must be carefully monitored by stakeholders and independent persons within the local and state government to ensure fairness. After all, the health care system is built on trust and when community members think that health workers are not qualified to care for their ward or themselves, it affects the utilization of the facility. Care must, however, be taken in the implementation of these strategies because beneficiaries of corrupt practices have been known to oppose any plan to alter the status quo [35].

Overall, our study emphasised the importance of grass-root approach that is broad-based and empowers community stakeholders to act unanimously on issues affecting PHCs. Synergy with community leaders, health workers, and government at both the local and state level can help speed up this process. It is nonetheless important to gain localised support from powerful persons, agencies and organisations in community settings who will help enforce the effort to reduce the influence of powerful persons [19] in the siting and functioning of PHCs. Adie et al [36] had earlier found that small communities can evolve health care services through active community participation. However, one limitation of this approach is that it is always difficult to get powerful agencies or organisations to support anticorruption struggles without incentives. Despite, there would however be chances for greater success when localised support is gained from powerful agencies, persons and organisations who stand to gain if the performance of PHCs improve tremendously.

\section{Conclusion}

Political actors and influential persons were found to have a strong influence on the activities surrounding the siting of primary health centres, recruitment of staff and sanctioning of staff. Hence, to reduce politicking in $\mathrm{PHCs}$, local and state government must learn to partner with community stakeholders when the need to make decisions on PHCs arise. This promises to improve access and utilisation of PHCs and further increase the gains towards attaining UHC. 


\section{Abbreviations}

PHCs

Primary Health Centres; UHC:Universal Health Coverage; HFCC:Health Facility Committee Chairmen; WHO:World Health Organisation; ACE:Anti-Corruption Evidence; FGD:Focused Group Discussion.

\section{Declarations}

\section{Acknowledgment}

These findings form part of a larger multi-country anti-corruption evidence (ACE) study in Bangladesh, Nigeria and Tanzania by SOAS University of London, United Kingdom (UK), in partnership with the London School of Hygiene and Tropical Medicine (LSHTM), UK, and the University of Nigeria, Nsukka (Enugu-campus). We thank Drs Dina Balabanova and Eleanor Hutchison for their assistance in the study.

\section{Author's contributions}

Conception and design: AO, OO; Acquisition of data: AO, PO, CO, PA; Analysis and interpretation of data: $A O, P O, C O, P A$; Drafting of the manuscript: $A O$; Critical revision of the manuscript for important intellectual content: AO, PO, CO, PA, OO; Supervision: 00.

\section{Funding}

The ACE research consortium is funded by the UK Department for International Development (DFID).

\section{Ethics approval and consent to participate}

Ethical approval was granted by the Health Research Ethics Committee of the University of Nigeria Teaching Hospital, Ituku-Ozalla, Nigeria. Also, study participants provided written and verbal informed consent obtained before taking part in the study.

\section{Availability of data and materials}

The datasets used and/or analysed during the current study are available from the corresponding author on reasonable request.

\section{Competing interests}

The authors declare that they have no competing interests.

\section{Author details}

${ }^{1}$ Department of Sociology \& Anthropology, University of Nigeria, Nsukka 
${ }^{2}$ Health Policy Research Group, Department of Pharmacology and Therapeutics, College of Medicine, University of Nigeria

${ }^{3}$ Department of Philosophy, Enugu State University of Science and Technology

${ }^{4}$ Department of Psychology, University of Nigeria, Nsukka

${ }^{5}$ Department of Social Work, University of Nigeria, Nsukka

${ }^{6}$ Department of Health Administration and Management, University of Nigeria, Enugu Campus, Nigeria.

\section{References}

1. WHO. Health in 2015: from MDGs to SDGs. Geneva: World Health Organization. 2015. http:// www.who.int/gho/publications/mdgs-sdgs/en/

2. Obioha EE, Molale GM. Functioning and Challenges of Primary Health Care (PHC) Program in Roma Valley, Lesotho. Ethno Medicine. 2011; 5:73-88.

3. WHO. Health in the green economy - health care facilities. Avenue Appia, Geneva: World Health Organisation. n.d. https://www.who.int/hia/green_economy/en/

4. Cich CB. Four criteria for selecting health centre sites. Health Facility Management. 2017. https://www.hfmmagazine.com/articles/3116-four-criteria-for-selecting-health-care-sites

5. Dell'Ovoa M, Capolongoa S, Oppio A. Combining spatial analysis with MCDA for the siting of healthcare facilities. Land Use Policy. 2018; doi.org/10.1016/j.landusepol.2018.02.044

6. Onwujekwe O, Orjiakor CT, Hutchinson E, Mckee M, Agwu P, Mbachu C, et al. Where do we start? Building consensus on drivers of health sector corruption in Nigeria and ways to address it. Int $\mathrm{J}$ Health Policy Manag. 2020; doi:10.15171/ijhpm.2019.128 
7. Hutchinson E, Balabanova D, McKee M. We need to talk about corruption in health systems. Int J Health Policy Manag. 2019; doi:10.15171/ijhpm.2018.123

8. Bambra C, Fox D, Scott-Samuel A. Towards a politics of health. Health Promotion and Insitutional. 2005; doi:10.1093/heapro/dah608.

9. Vredenburgh D, Shea Van-Fossen R. Human Nature, Organizational Politics and Human Resource Development. Human Resource Development Review. 2010; 9: 26-47.

10. Stalter A, Arms D. Serving on organizational boards: what nurses need to know. OJIN: The Online Journal of Issues in Nursing,2016; doi: 10.3912/OJIN.Vol21No02PPT01

11. Silverman M, White D. Hospital politics don't have to be dirty business. Emergency Physicians Monthly. 2017. https://epmonthly.com/article/hospital-politics-dont-dirty-business/

12. Ojiabo UJTN, Alagah AD. Organisational politics and employee's job satisfaction in the health sector of Rivers State. International Journal of Advanced Research. 2017; 3:88-106.

13. Dubrin AJ. Fundamentals of organizational behaviour. USA: Thomas Higher Education; 2007.

14. Onwujekwe O, Agwu P, Orjiakor C, Mckee M, Hutchinson E, Odii A, et al. Corruption in Anglophone West Africa health systems: a systematic review of its different variants and the factors that sustain them. Health Policy and Planning. 2019; Doi: 10.1093/heapol/czz070

15. Robbins SP, Judge TA. Organizational Behaviour. $15^{\text {th }}$ ed. Indianapolis: Pearson Education, Inc; 2011.

16. Mubyazi MG, Hutton G. Rhetoric and reality of community participation in health planning, resource allocation and service delivery: a review of the reviews, primary publications and grey literature. Rwanda Journal of Health Sciences. 2012; 1:51-65. 
17. Azuh D. Corruption and other challenges facing health care delivery at the grassroots level in Nigeria. State and Society. 2012; 2: 1-10.

18. Anyika NE. Challenges of implementing sustainable health care delivery in Nigeria under environmental uncertainty. Journal of Hospital Administration. 2014; doi:10.5430/jha.v3n6p11.

19. Khan M, Andreoni A, Roy P. Anti-Corruption in adverse contexts: a strategic approach. London: SOAS. 2016. https://eprints.soas.ac.uk/23495/1/Anti-Corruption\%20in\%20Adverse\%20Contexts\%20(1).pdf

20. Wong J. (2015). Achieving universal health coverage. Bulletin of the World Health Organization. 2015; doi. http://dx.doi.org/10.2471/BLT.14.149070

21. National Population Commission (NPC). Population census of the federal republic of Nigeria: Preliminary Report United Nations Population Division (2005). Abuja, Nigeria: NPC; 2006.

22. Onwujekwe O, Uzochukwu BS, Ezumah N. The district health system in Enugu State: an analysis of policy development and implementation. African Journal of Health Economics. 2014; 3:1-14.

23. Braun V, Clarke V. Using thematic analysis in psychology. Qualitative Research in Psychology. 2006; 3: 77-101.

24. Oluwamotemi KD. Land acquisition, compensation and resettlement in developing economies: Nigeria as a case study. FIG congress - facing the challenges and building the capacity. 2010.

25. Rasak BO. Patrons' perception of healthcare services in Primary Health Centres (PHCs) in Oyo State, Nigeria. Developing Country Studies. 2013; 3:75-84.

26. Alfaqeeh AG. Access and utilisation of primary health care services in Riyadh Province, Kingdom of Saudi Arabia (Doctoral Thesis, University of Bedfordshire). Available from University of Bedfordshire Database; 2015. 
27. Ojo SJ, Lamidi OK, Odewale DA, Shiyanbade B, Ihemeje G. Enemy within the state: the pathology of boko haram insurgency, military corruption, and fallacy of arms procurement in Nigeria. International Journal of Public Administration. 2019; doi: 10.1080/01900692.2019.1665068

28. Sharma SP. Politics and corruption mar health care in Nepal. The Lancet. 2010; doi.org/10.1016/S0140-6736

29. Vian T. Review of corruption in the health sector: theory, methods and interventions. Health Policy and Planning. 2008; 23:83-94

30. Lewis M. Governance and corruption in public health care systems. Centre for Global Development (Working Paper No. 78). 2006. http://www1.worldbank.org/publicsector/anticorrupt/Corruption\%20WP_78.pdf

31. Ogbuabor CD, Onwujekwe 0 . Implementation of free maternal and child healthcare policies: assessment of influence of context and institutional capacity of health facilities in South-east Nigeria, Global Health Action. 2018; doi:10.1080/16549716.2018.1535031

32. Jaro IM, Ibrahim AA. The accessibility problems of primary healthcare to rural people in Jigawa State, Nigeria. Global Advanced Research Journal of Soc Sci. 2014; 1:072-076.

33. Callen M, Gulzar S, Hasanain AS, Khan Y. The Political Economy of Public Sector Absence: Experimental Evidence from Pakistan (Working paper no 22340). 2016. http://scholar.harvard.edu/files/michael-callen/files/pe_absence_june5.pdf?m=1466002769

34. Onwujekwe O, Odii A, Agwu P, Orjiakor C, Ogbozor P, Mckee, M, et al. Exploring health-sector absenteeism and feasible solutions: evidence from the primary healthcare level in Enugu, southeast Nigeria. London: SOAS-ACE Research Consortium. 2019a. https://ace.soas.ac.uk/wpcontent/uploads/2019/09/ACE-WorkingPaper014-NigeriaAbsenteeism-190916.pdf 
35. Johnsøn J, Taxell N, Zaum D. Mapping evidence gaps in anti-corruption: Assessing the state of the operationally relevant evidence on donors' actions and approaches to reducing corruption. Anticorruption Resource Centre. 2012. https://www.u4.no/publications/mapping-evidence-gaps-in-anticorruption-assessing-the-state-of-the-operationally-relevant-evidence-on-donors-actions-andapproaches-to-reducing-corruption/

36. Adie $\mathrm{H}$, Igbang $\mathrm{T}$, Out $\mathrm{A}$, Braide $\mathrm{E}$, Okon $\mathrm{O}$, Ikpi E, et al. Strengthening primary healthcare through community involvement in Cross River State, Nigeria: A descriptive study. PanAfrican Medical Journal. 2014; doi.org/10.11604/pamj.2014.17.221.2504

\section{Tables}

Table 1: Sociodemographic characteristics of participants

\begin{tabular}{|c|c|c|c|c|c|}
\hline $\mathrm{S} / \mathrm{n}$ & LGA & Position & Education & Sex & Age \\
\hline 1 & Ibagwani & OIC & $1^{\text {st }}$ degree & $\mathrm{F}$ & 46 \\
\hline 2 & Ibagwani & HFCC & M.Sc. & M & 61 \\
\hline 3 & Ibagwani & FGD Service users & Primary - Secondary & Ms & $38-84$ \\
\hline 4 & Ibagwani & CHEW & OND & $\mathrm{F}$ & 45 \\
\hline 5 & Ibagwani & Divisional HOD & M.Sc. & $\mathrm{F}$ & 48 \\
\hline 6 & Nsukka & Midwife & OND & $\mathrm{F}$ & 25 \\
\hline 7 & Nsukka & HOD & $1^{\text {st }}$ degree & $\mathrm{F}$ & 42 \\
\hline 8 & Nsukka & FGD Service users & Primary - secondary & Fs & $30-76$ \\
\hline 9 & Nsukka & OIC & $1^{\text {st }}$ degree & $\mathrm{F}$ & 42 \\
\hline 10 & Nsukka & HFCC & $1^{\text {st }}$ degree & M & 47 \\
\hline 11 & Igbo-Etiti & FGD Service users & Junior sec. school - 1st degree & Fs & $18-35$ \\
\hline 12 & Igbo-Etiti & HOD & $1^{\text {st }}$ degree & M & 50 \\
\hline 13 & Igbo-Etiti & CHEW & OND & $\mathrm{F}$ & 29 \\
\hline 14 & Igbo-Etiti & HFCC & $1^{\text {st }}$ degree & M & 45 \\
\hline 15 & Igbo-Etiti & OIC & $1^{\text {st }}$ degree & $\mathrm{F}$ & 40 \\
\hline 16 & Oji-River & OIC & $1^{\text {st }}$ degree & $\mathrm{M}$ & 42 \\
\hline 17 & Oji-River & CHEW & OND & $\mathrm{F}$ & 40 \\
\hline 18 & Oji-River & FGD Service users & No formal Edu. - M.Sc. & Ms & $27-76$ \\
\hline 19 & Oji-River & HOD & $1^{\text {st }}$ degree & $\mathrm{F}$ & 49 \\
\hline 20 & Oji-River & HFCC & $1^{\text {st }}$ degree & M & 57 \\
\hline
\end{tabular}

Table 2: Designation and status of participants across LG 


\begin{tabular}{llllll}
\hline Designation & Status & Nsukka & Oji-River & Ibagwa-Ani & Igbo-Etiti \\
\hline Health administrator & HOD & 1 & 1 & 1 & 1 \\
Facility head & OIC & 1 & 1 & 1 & 1 \\
\hline Health worker & NURSE/CHEW/MIDWIFE & 1 & 1 & 1 & 1 \\
\hline Health chairman & HFCC & 1 & 1 & 1 & 1 \\
\hline Service users & FGD- men/Women & 1 & 1 & 1 & 1 \\
\hline
\end{tabular}

